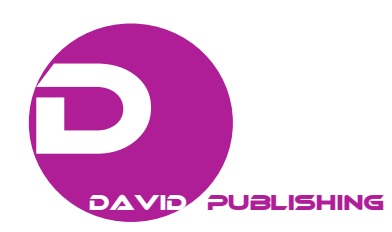

\title{
Nurses: Extending Care through Telehealth
}

\author{
Maryah, ALLEN ${ }^{1,2}$, Mya, AYLOTT ${ }^{1}$, Margarita, LOYOLA ${ }^{1,2}$, Mika, MORIC $^{1,2}$ and Lisa, SAFFAREK ${ }^{1}$ \\ 1. Island Health Telehealth, Victoria, BC V8R 1J8, Canada \\ 2. Island Health Telehealth, Nanaimo, BC V9S 2B7, Canada
}

\begin{abstract}
Nurses have an immense impact on the growth and scope of Telehealth as they embrace diverse roles. TeleNursing introduces transformational change which positively impacts both clients and providers, increasing access to care and reducing the time and costs associated with traveling for health care. Integration of clinical support and remote diagnostic tools inspire new uses of Telehealth, thus enabling care previously only possible in person to be delivered virtually. Nurses currently leverage Telehealth to deliver care and education, monitor clients remotely and support medical consultations. Over $90 \%$ of Island Health nurses surveyed recommend Telehealth as a care modality to clients and $100 \%$ support Telehealth as a means to increase care to vulnerable communities. Programs wish to increase uptake of TeleNursing but face numerous challenges regarding funding, resourcing, scheduling and geographical ownership. TeleNursing goes beyond clinical support and has the potential to exponentially expand Telehealth services, normalizing Telehealth as a care modality. Nurses look to Telehealth to improve their ability to partner with clients over distance, providing surgical care, maternal/pediatric care and group education
\end{abstract}

Key words: Telehealth, TeleMedicine, TeleNursing.

\section{Introduction}

Telehealth refers to the use of communications and information technology to deliver healthcare services and information over distances [1]. Telehealth is a common modality to provide care at Island Health, an authority responsible for providing health services to over 760,000 people on the west coast of British Columbia.

Since implementation in 2007, Island Health Telehealth has grown exponentially and is embedded within many clinical programs. Technological advances, such as digital stethoscopes and exam cameras, have pushed Telehealth to a new paradigm where providers can physically assess their clients over distance. Nurses are often required at the client site to facilitate medical assessments, thus enabling remote consultations. In addition to providing clinical support, nurses are beginning to use Telehealth to provide distant client care and education (often referred to as TeleNursing) [2]. Professional bodies,

Corresponding Author: Margarita Loyola, P. Eng., M. Eng, MBA, CCE, research field: Telehealth. Email: Margarita.Loyola@viha.ca. such as the Canadian Nurses Association, support Telehealth in nursing practice and its potential to enhance healthcare services [3]. This paper addresses TeleNursing impacts, insights and challenges while examining additional opportunities for nurses to incorporate Telehealth into clinical practice.

\section{Telehealth and Nursing at Island Health}

At Island Health, nurses use Telehealth to monitor clients remotely, deliver care and education and provide clinical support during medical consultations. There are several Island Health programs that routinely use clinical support during their Telehealth sessions [4]: Cardiology, Renal, Speech Language Pathology and Geriatrics. TeleNursing is expanding through Home Health Monitoring and Wound Care, by providing distant client care and education. The number of Telehealth consultations with clinical support has grown dramatically (Table 1), expanding more than $300 \%$ last year [5].

\subsection{Monitoring Clients Remotely}

HHM (home health monitoring) is an initiative that 
supports clients in monitoring chronic conditions. Nurses provide heart failure education and partner with clients to improve self-management skills and track symptoms. The HHM program empowers clients to improve management of their heart health. Clients take their own vital signs and self-assess their wellbeing using a remote and wireless tablet with ancillary biometric capturing tools that transmits a daily care plan to the nurse. Home and Community Care nurses monitor the clients' results remotely and help clients gain a better understanding of heart conditions and early detection of health changes to prevent hospitalization. HHM has a significant impact on outcomes, resulting in $67 \%$ reduction in hospital admissions, $75 \%$ reduction in length of hospital stay, and $65 \%$ reduction in emergency room visits at Island Health (2014).

\subsection{Delivering Care and Education via Telehealth}

Nurses regularly use Telehealth to provide care remotely to clients. For example, Island Health Kidney Care Clinic nurses deliver client education and services via Telehealth, allowing them to connect to multiple communities simultaneously. Kiyomi Renville, a renal nurse and Telehealth advocate, states that "Telehealth has increased access to education for clients and has had a positive impact on overall health and quality of care". Similarly, cardiology nurses use Telehealth to deliver education sessions to clients living with atrial fibrillation.

\subsection{Supporting Medical Consultations}

Many Island Health programs require clinical support at the client site to assess vital signs, perform physical assessments, and operate Telehealth diagnostic devices. Consultations take place in designated Telehealth rooms located in health care facilities leveraging locally available nurses.

For example, the Heart Health program relies on nurses at the client site to take vital signs and use a digital stethoscope which transmits heart and lung sounds. During the appointment, the remote specialist collaborates with the nurse in real-time, guiding optimal placement of the stethoscope. More than 270 cardiology sessions have successfully been delivered via Telehealth to Island Health clients.

Seniors Outpatient Clinic nurses use Telehealth to collaborate with geriatricians remotely while conducting cognitive assessments, strength tests, and physical assessments. As elderly clients generally have a variety of mental and physical conditions, strong communication between local nurses and the geriatrician is essential for client care. With dementia being a possible barrier to Telehealth, nurses assess the suitability of Telehealth for each client and advise the geriatrician of additional observations during sessions [6].

The Speech Language Pathology program uses Telehealth to conduct swallowing assessments and speech therapy remotely. In a typical session, a SLP (speech language pathologist) works with the client and a supporting clinician (nurse, occupational therapist, dietitian, or rehabilitation assistant). The SLP performs a swallowing assessment by remotely zooming in with a high definition camera. The supporting clinician palpates and describes the client's throat to augment the assessment. At Island Health, the use of Telehealth by SLPs has improved patient outcomes by reducing client transfers and enabling faster access to care for medically unstable clients [7].

Table 1 Growth of Telehealth consultations within Island Health.

\begin{tabular}{lll}
\hline Fiscal year & Total Telehealth consultations & Telehealth consultations using clinical support \\
\hline $2011 / 2012$ & 2,042 & 3 \\
$2012 / 2013$ & 2,522 & 133 \\
$2012 / 2013$ & 3,648 & 343 \\
\hline
\end{tabular}


Requests for consultations requiring client site clinical support is increasing, both within and outside of Island Health. If client site clinical support were always available, more programs would employ Telehealth as a modality, helping equalize access to care in vulnerable communities.

\section{Nursing Impact on Telehealth}

The inclusion of clinical support during Telehealth consultations has had an immense impact at Island Health. Without Telehealth clinical support, more clients would be without specialty care or required to travel. Before Telehealth, the only options for remote clients to receive clinical education were via mail, telephone, or to travel [8]. Additional programs, such as multiple sclerosis and rehabilitation, are beginning to explore Telehealth as a viable care modality option given the availability of client site clinical support.

\section{The Impact of Telehealth on Nursing Practice}

Nurses experience multiple benefits from Telehealth, including decreased clinical isolation, reduced patient transfers, education opportunities and ability to further support community based care. Nurses working remotely can connect with physicians, colleagues, and access unique education opportunities, linking them to clinical networks otherwise inaccessible. In both remote and central facilities, nurses can use Telehealth to discuss clients' health plans, procedures and general medical conditions with physicians and other care-team members.

Telehealth reduces patient transfers and associated nursing tasks: preparing and accompanying the patient, completing paperwork, booking the ambulance, and communicating with the family [7, 9].Instead of transfers disrupting client care and nursing workflow, nurses can facilitate specialty consultations via Telehealth.

\section{Island Health Nurses Perspective on Telehealth}

Island Health Telehealth surveyed 53 nurses to better understand their opinion of Telehealth (Appendix A). Of those surveyed, 40\% had direct Telehealth experience (Table 2). Survey responses were positive with more than $90 \%$ of nurses stating they would recommend Telehealth to clients and providers. All nurses surveyed agreed that Telehealth increases access to specialist care. One nurse commented that "What I like most about Telehealth is the improvement in the 'patient journey' across the Island. It [Telehealth] saves our complex, chronically ill patients considerable travel time, money and energy to be able to access specialty care in their own communities" [10]. Of surveyed nurses not currently using Telehealth, $66 \%$ see opportunity to use it within their practice and $90 \%$ foresee potential to improve client continuity of care (Appendix B).

\section{Challenges}

Some challenges have surfaced with increased use and adoption of Telehealth at Island Health: emphasized need for clinical support at the client site, scarcity of resources, scheduling, funding, and geographic ownership. Providing support for Telehealth consultations is a relatively new clinical task and creates additions to daily workflows. Programs are requesting remote clinical support in cases where nursing would not normally have been part

Table 2 Perspectives from nurses who have direct Telehealth experience.

\begin{tabular}{llllll}
\hline $\begin{array}{l}\text { Do you agree with the following: } \\
\text { Telehealth has the potential of }\end{array}$ & Strongly agree & Agree & Disagree & \multicolumn{2}{l}{ Strongly disagree } \\
\hline Improving access to quality care & $14(70 \%)$ & $6(30 \%)$ & $0(0 \%)$ & $0(0 \%)$ & 20 \\
$\begin{array}{l}\text { Helping move towards community } \\
\text { based care }\end{array}$ & $13(65 \%)$ & $6(30 \%)$ & $1(5 \%)$ & $0(0 \%)$ & 20 \\
Improving access to specialist care & $13(65 \%)$ & $7(35 \%)$ & $0(0 \%)$ & $0(0 \%)$ & 20 \\
\hline
\end{tabular}


of the client's care. Clinical shortages and budget restrictions make it difficult for managers to find nursing hours for Telehealth. Local client care often conflicts with Telehealth consultations, necessitating rescheduling of the consultation.

The funding and ownership of Telehealth clinical support is a grey area within Island Health. For example, one community hospital advocates for local care and therefore delivers clinical support by adding Telehealth consultations to their ambulatory slate. Others look to Telehealth for funding of clinical support or struggle to find available nursing hours.

\section{Opportunities for Expansion in Nursing Practice}

Nurses view Telehealth as a tool to better serve clients and wish to integrate Telehealth into their practice. Surveyed Island Health nurses recommend Telehealth be adopted into the following programs: pre and post-operative consultations, breast feeding assessments, maternal care, pediatric consultations, diabetes group meetings, and respiratory care. Emergency and Intensive Care Units are also opportunities for nursing in Telehealth [11].

As health authorities focus on primary care and clients as partners, there is an opportunity to extend Telehealth into client homes. For example, CHW (community health workers) currently observe medication adherence by visiting clients in their homes. Nurses are required to confirm sliding scale insulin dosages, as this falls outside the scope of CHWs. Telehealth in the home allows nurses to remotely verify correct dosages of insulin injections, increasing efficiency and eliminating time lost to travel.

Island Health Telehealth is actively strategizing to address the above challenges, with the intention to create seamless transition of embedding Telehealth into nursing practice. Current restructuring of Island Health into new geographic areas will encourage local ownership of client care, hopefully increasing access to Telehealth clinical support.

\section{Conclusion}

Clinical support and remote diagnostic technologies create a paradigm shift where Telehealth is embedded in our health care system. Remote physical examinations are enabled, preventing countless kilometers of travel for both clients and providers. Support from leadership and clinical champions are essential in supporting this transformational change. Care providers have the option of using Telehealth to expand delivery of services and work with clients remotely. With the increasing interest and desire to incorporate Telehealth in nursing practice, there will be an exponential growth in the utilization of Telehealth technology.

\section{References}

[1] "Canada Health Infoway." Canada Health Infoway. N. p., n.d. Web. $\quad 10 \quad$ Sept. 2014. https://www.infoway-inforoute.ca.

[2] American Telemedicine Association (2011, April). Telehealth Nursing Fact Sheet: ATA Telehealth Nursing SIG. [fact sheet. Retrieved from http://www.americantelemed.org/docs/default-documentlibrary/fact_sheet_final.pdf?sfvrsn=2.

[3] Canadian Nurses Association. (2014). Position Statement Telehealth: The Role of the Nurse. Retrieved from http://cna-aiic.ca/ /media/cna/page-content/pdf-en/ps89_t elehealth_e.pdf.

[4] Island Health. (2014). Telehealth as a Care Delivery Option [Fluid Survey].

[5] Island Health. (2014). Telehealth. Retrieved July $20^{\text {th }}$, 2014

from

https://intranet.viha.ca/departments/imit/telehealth/Pages/ default.aspx.

[6] Esterle, L., and Mathieu, F. A. 2013. "Teleconsultation in Geriatrics: Impact on Professional Practice." International Journal of Medical Informatics 82: 684-95.

[7] Sheridan, Sarah. (2014, July 11th). Telephone interview.

[8] Renville, Kiyomi. (2014, June 30th) Telephone interview.

[9] Mills, Christina. (2014, July 16th) Telephone interview.

[10] Island Health Nurse. (2014, July 13th). Survey Response.

[11] Williams, L. M., Hubbard, K. E., Daye, O., and Barden, C. 2012. "Telenursing in the Intensive Care Unit: Transforming Nursing Practice." Critical care nurse 32: 62-9. 


\section{Appendix A: Nurses with Direct Telehealth Experience - Survey Results}

Do you agree with the following? Telehealth has the potential of:

\begin{tabular}{llllll}
\hline & $\begin{array}{l}\text { Strongly } \\
\text { Agree }\end{array}$ & Agree & Disagree & $\begin{array}{l}\text { Strongly } \\
\text { Disagree }\end{array}$ & $\begin{array}{l}\text { Total } \\
\text { Responses }\end{array}$ \\
\hline Improving access to quality care & $0(0 \%)$ & $0(0 \%)$ & $0(0 \%)$ & $0(0 \%)$ & 0 \\
\hline $\begin{array}{l}\text { Helping move towards community } \\
\text { based care }\end{array}$ & $0(0 \%)$ & $0(0 \%)$ & $0(0 \%)$ & $0(0 \%)$ & 0 \\
\hline $\begin{array}{l}\text { Increasing access to health in vulnerable } \\
\text { communites }\end{array}$ & $0(0 \%)$ & $0(0 \%)$ & $0(0 \%)$ & $0(0 \%)$ & 0 \\
\hline $\begin{array}{l}\text { Improving access to specialist care } \\
\text { Facilitating education opportunities for } \\
\text { healthcare professionals }\end{array}$ & $0(0 \%)$ & $0(0 \%)$ & $0(0 \%)$ & $0(0 \%)$ & 0 \\
\hline $\begin{array}{l}\text { Giving healthcare professionals } \\
\text { additional options for providing care }\end{array}$ & $0(0 \%)$ & $0(0 \%)$ & $0(0 \%)$ & $0(0 \%)$ & 0 \\
\hline $\begin{array}{l}\text { Improving continuity of care } \\
\text { Imp }\end{array}$ & $0(0 \%)$ & $0(0 \%)$ & $0(0 \%)$ & $0(0 \%)$ & 0
\end{tabular}

How often do you participate in Telehealth?

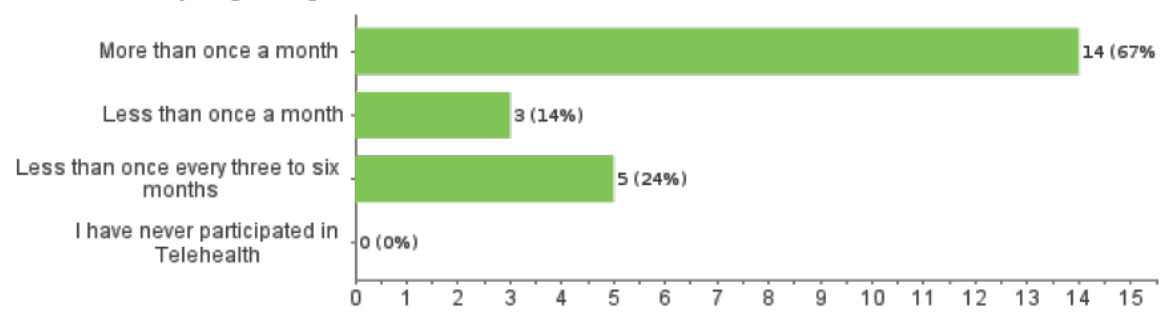

Have you used the following?

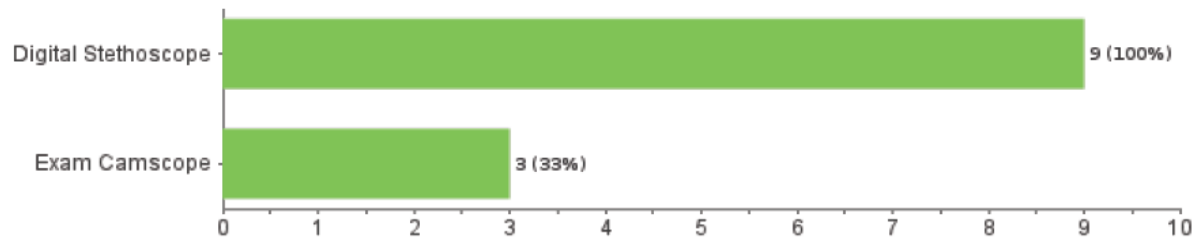

Who would you recommend Telehealth to?

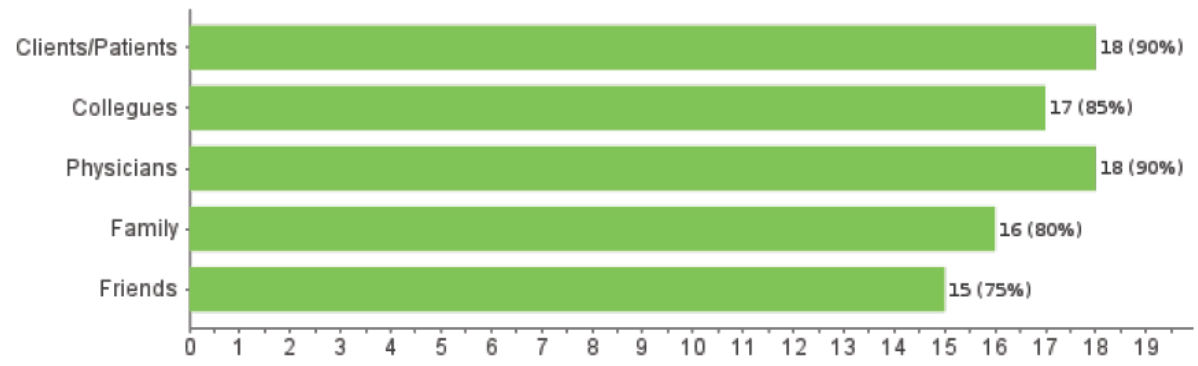


Do you agree with the following? Telehealth has the potential of:

\begin{tabular}{llllll}
\hline & $\begin{array}{l}\text { Strongly } \\
\text { Agree }\end{array}$ & Agree & Disagree & $\begin{array}{l}\text { Strongly } \\
\text { Disagree }\end{array}$ & $\begin{array}{l}\text { Total } \\
\text { Responses }\end{array}$ \\
\hline Improving access to quality care & $14(70 \%)$ & $6(30 \%)$ & $0(0 \%)$ & $0(0 \%)$ & 20 \\
\hline $\begin{array}{l}\text { Helping move towards community } \\
\text { based care }\end{array}$ & $13(65 \%)$ & $6(30 \%)$ & $1(5 \%)$ & $0(0 \%)$ & 20 \\
\hline $\begin{array}{l}\text { Increasing access to healthcare in } \\
\text { vulnerable communities }\end{array}$ & $13(65 \%)$ & $6(30 \%)$ & $1(5 \%)$ & $0(0 \%)$ & 20 \\
\hline $\begin{array}{l}\text { Improving access to specialist care } \\
\text { Facilitating education opportunities for } \\
\text { healthcare professionals }\end{array}$ & $11(55 \%)$ & $9(45 \%)$ & $0(0 \%)$ & $0(0 \%)$ & 20 \\
\hline $\begin{array}{l}\text { Giving healthcare professionals } \\
\text { additional options for providing care }\end{array}$ & $11(55 \%)$ & $9(45 \%)$ & $0(0 \%)$ & $0(0 \%)$ & 20 \\
\hline $\begin{array}{l}\text { Improving continuity of care } \\
\text { Overall I am satisfied with Telehealth }\end{array}$ & $11(55 \%)$ & $9(45 \%)$ & $0(0 \%)$ & $0(0 \%)$ & 20 \\
\hline $\begin{array}{l}\text { My Telehealth training was adequate } \\
\text { for me to support my clients }\end{array}$ & $7(35 \%)$ & $9(45 \%)$ & $3(15 \%)$ & $1(5 \%)$ & 20 \\
\hline
\end{tabular}

\section{Appendix B: Nurses without Telehealth Experience-Survey Results}

Do you see an opportunity to use Telehealth in your practice?

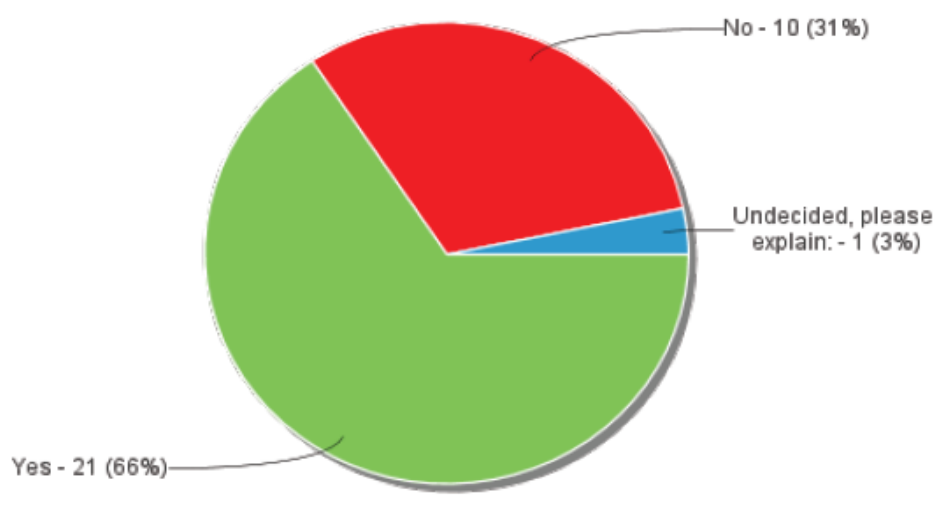

Do you agree with the following? Telehealth has the potential of:

\begin{tabular}{llllll}
\hline & $\begin{array}{l}\text { Strongly } \\
\text { Agree }\end{array}$ & Agree & Disagree & $\begin{array}{l}\text { Strongly } \\
\text { Disagree }\end{array}$ & $\begin{array}{l}\text { Total } \\
\text { Responses }\end{array}$ \\
\hline Improving access to quality care & $14(47 \%)$ & $14(47 \%)$ & $2(7 \%)$ & $0(0 \%)$ & 30 \\
\hline $\begin{array}{l}\text { Helping move towards community } \\
\text { based care }\end{array}$ & $12(41 \%)$ & $15(52 \%)$ & $2(7 \%)$ & $0(0 \%)$ & 29 \\
\hline $\begin{array}{l}\text { Increasing access to health in } \\
\text { vulnerable communites }\end{array}$ & $17(57 \%)$ & $13(43 \%)$ & $0(0 \%)$ & $0(0 \%)$ & 30 \\
\hline Improving access to specialist care & $17(57 \%)$ & $11(37 \%)$ & $2(7 \%)$ & $0(0 \%)$ & 30 \\
\hline $\begin{array}{l}\text { Facilitating education opportunities for } \\
\text { healthcare professionals }\end{array}$ & $13(43 \%)$ & $17(57 \%)$ & $0(0 \%)$ & $0(0 \%)$ & 30 \\
\hline $\begin{array}{l}\text { Giving healthcare professionals } \\
\text { additional options for providing care }\end{array}$ & $15(50 \%)$ & $14(47 \%)$ & $1(3 \%)$ & $0(0 \%)$ & 30 \\
\hline $\begin{array}{l}\text { Improving continuity of care } \\
13(43 \%)\end{array}$ & $14(47 \%)$ & $3(10 \%)$ & $0(0 \%)$ & 30
\end{tabular}

